OPEN ACCESS

Edited by:

Liansong Xiong,

Nanjing Institute of Technology (NUIT),

China

Reviewed by:

Xiong Wu,

Xi'an Jiaotong University, China Stefano Leonori,

Sapienza University of Rome, Italy

*Correspondence:

Yaojie Sun

yjsun@fudan.edu.cn

Specialty section:

This article was submitted to

Process and Energy Systems

Engineering,

a section of the journal

Frontiers in Energy Research

Received: 11 July 2021

Accepted: 13 August 2021

Published: 13 September 2021

Citation:

Li T, Tao S, He K, LU M, Xie B, Yang B and Sun Y (2021) V2G Multi-Objective

Dispatching Optimization Strategy

Based on User Behavior Model.

Front. Energy Res. 9:739527.

doi: 10.3389/fenrg.2021.739527

\section{V2G Multi-Objective Dispatching Optimization Strategy Based on User Behavior Model}

\author{
Tianyu $\mathrm{Li}^{1,2,3}$, Shengyu Tao ${ }^{1,3,4}$, Kun $\mathrm{He}^{1,3}$, Mengke $\mathrm{Lu}^{5}$, Binglei $\mathrm{Xie}^{2}$, Biao Yang ${ }^{2}$ and \\ Yaojie Sun ${ }^{1,3,4 *}$
}

${ }^{1}$ School of Information Science and Technology, Fudan University, Shanghai, China, ${ }^{2}$ School of Architecture, Harbin Institute of Technology Shenzhen, Shenzhen, China, ${ }^{3}$ Shanghai Engineering Research Centre for Artificial Intelligence and Integrated Energy System, Shanghai, China, ${ }^{4}$ Institute for Six-Sector Economy, Fudan University, Shanghai, China, ${ }^{5}$ State Grid Zhejiang Electric Power Co., Ltd, Hangzhou, China

V2G (Vehicle to Grid) technology can adjust the grid load through the unified control of the charging and discharging of electric vehicles (EVs), and achieve peak shaving and valley filling to smooth load fluctuations. Aiming at the random and uncertain problem of EV users travel and behavior decision-making, this paper proposes a V2G multi-objective dispatching strategy based on user behavior. First, a V2G behavior model was established based on user behavior questionnaire surveys, and the effective effect of EV load was simulated through Monte Carlo simulation. Then, combined with the regional daily load curve and peak-valley time-of-use electricity prices, with the goal of stabilizing grid load fluctuations and increasing the benefits of EV users, a multi-objective optimal dispatching model for EV clusters charging and discharging is established. Finally, Considering the needs of EV users and the operation constraints of the microgrid, the genetic algorithm is used to obtain the Pareto optimal solution. The results show that when dispatching with the maximum benefit of users, the peak-to-valley ratio of the grid side can be reduced by $2.99 \%$, and the variance can be reduced by $9.52 \%$. The optimization strategy can use peak and valley time-of-use electricity prices to guide the intelligent charging and discharging of EVs while meeting user needs, so as to achieve the optimal multi-objective benefit of V2G participation in power response.

Keywords: V2G, user behavior, Monte Carlo simulation, grid load dispatching, multi-objective optimization

\section{INTRODUCTION}

Electric vehicles (EVs) have the dual attributes of transportation and energy storage, with great potential and value in the application of energy Internet. According to the US National Household Travel Survey, EVs are idle 96\% of the time (Kempton and Tomić, 2005; Yonghua et al., 2012). On the one hand, EVs can be used as distributed energy storage on the user side of the power system after they are connected to the grid on a large scale, helping to connect distributed renewable energy power generation and regulating the power load of the grid under low inertia and high intermittency circumstances (Xiong et al., 2020a). On the other hand, EVs can be used as distributed power sources to provide power in the opposite direction to the grid, play the role of peak shaving and valley filling as auxiliary services, i.e., frequency modulation and backup energy storage. Vehicle-to-Grid (V2G) technology embraces the two aforementioned purposes as one:a technology that enables energy to be pushed back to the power grid from the battery of EVs (Soares et al., 2016; Wei and Li, 2017; Xing 
et al., 2021; Xue et al., 2021; Zeng et al., 2021). According to the report "Research on the Potential and Economics of Electric Vehicle Energy Storage Technology" issued by the National Development and Reform Commission's Energy Research Institute, China's electric vehicle ownership will exceed 80 million in 2030, and the theoretical energy storage potential of V2G will exceed $5000 \mathrm{GWh}$ (Jian, 2020). The application and development of V2G technology has huge potential.

V2G adjusts the available capacity when the grid load reaches the peak or valley. Through the large-scale charging and discharging behavior to perform peak shaving and valley filling, the grid load will be uniformed and further stabilized, which is of great importance to the modern power systems (Xiong et al., 2020b). However, as an EV cluster is an integration of multiple transportation units, its charge and discharge control are affected by factors such as user behavior, remaining battery capacity, and access time. Electric vehicle load has a high degree of randomness and volatility in time and space. Multifactor variables such as driving rules, user preferences, and access duration have brought great challenges to the orderly adjustment of V2G. Meanwhile, there are still many technical and policy issues in the application and promotion of V2G technology. When participating in $V 2 G$, it is first necessary to meet its travel needs, and secondly, regarding the impact of V2G on battery consumption as an economic consideration. An electric vehicle cluster is composed of multiple individual users. How to balance the grid-side regulation needs and the personal needs of electric vehicle users is a difficult problem to be solved.

Up to date, researches on the driving behavior of EVs and V2G regulation of grid load have been widely conducted (Li et al., 2020; Zhou et al., 2020; Leonori et al., 2021; Sangob and Sirisumrannukul, 2021). The MIT Energy Research Institute team established a Trip Energy model by tracking EV energy consumption data to analyze the impact of EV expansion caused by the improvement of charging facilities (Wei et al., 2021). Literature (Wu et al., 2018) introduced multi-agent integrated modeling based on experimental economics, and established a travel willingness model for EV users. Literature (Salehpour and Tafreshi, 2020) introduces a stochastic model for uncertainty handling in the interaction between a smart micro grid and EVss. To further describe the driving behaviors, researches on the statistical data upon National Household Vehicle Survey (NHTS) by considering EVs as equilibrium energy storage aggregator (Qian et al., 2011; Toquica et al., 2020). In terms of the V2G optimal dispatching, literature (Wu et al., 2018; Toquica et al., 2020) proposed an orderly charging control strategy for EVs guided by time-of-use electricity prices. Under the premise of considering user satisfaction, this strategy effectively smoothed the grid peak-valley difference, but did not study the probabilistic distribution of EV discharging to the grid. Literature (Dong et al., 2021) directly regulates the access of EVs to the grid from the perspective of the grid side to construct an economic dispatch model of the power system, with the satisfaction of the load-side car owners unconsidered, adversely promoting the enthusiasm of the V2G participation. Literature (Mahmud et al., 2018) uses the cross-entropy algorithm to solve the constructed load fluctuation model, which remains a single-objective optimization problem, ignoring the economic benefits of EV users and the load peakvalley difference after adjustment.

The above analysis indicates that most of the current research on the evaluation of the effect of V2G participation only considers traffic travel statistics and the response of the power grid separately, and it is difficult to accurately reflect the interaction between the EVs users and the power grid. Existing research has not comprehensively investigated multiple factors such as EVs user behaviors, preferences, and charging/discharging methods. V2G research based on EV user behavior and comprehensive consideration of grid-side load demand, user-side travel preferences and economic demand is rarely reported.

In order to solve the problem of the lack of accurate description of user behavior, this paper primarily collects EV driving data by conducting questionnaire surveys and searching for historical data. The impact of cluster charging/discharging on grid load is consequently analyzed. The EV charging/discharging behavior is simulated by Monte Caro method, and the influence of $\mathrm{V} 2 \mathrm{G}$ on the original load curve under different scenarios is studied. The optimization model is established with the goal of minimizing the grid load variance and maximizing the charging/ discharging revenues of EV users. Meanwhile, dispatching constraints are carried out according to the travel characteristics of EV users, and users are guided to discharge during peak periods of grid load and charge during valley periods. Finally, V2G under the microgrid in Shanghai is used as a case for verification. The genetic algorithm is used to obtain the Pareto optimal solution, and the optimization strategy of the electric vehicle cluster charging and discharging control is obtained. The behaviorally realistic model proposed for analyzing the effect of V2G participation essentially coordinates the user willingness and friendly operation of the power grid as a novel inspiration for future EV based energy storage systems. The structure of this paper is shown in Figure 1.

Figure 1 shows the research content and structure, including the V2G modeling solution based on user behavior and the V2G cluster scheduling platform under the regional microgrid An EV cluster refers to all EVs connected to the grid in a certain area as a whole. The dispatching platform summarizes the power status, power constraints and other information of all EVs through the monitoring system, and coordinates the load status dispatch of the regional microgrid. While considering the individual differences of users, the unified charge/discharge control of the EVs connected to the grid is carried out, and the power regulation tasks are consequentially allocated to the EVs. Meanwhile, the platform judges the charging/discharging behavior based on the feedback signal, so that the EV energy storage coordinately participates in the energy dispatching.

The research steps of this paper are: behavior investigationsimulation modeling-case verification. Introduction Section includes background and research background and literature review. Electric Vehicle Load Analysis Based on User Behavior Section establishes a V2G model that considers the behavior and energy characteristics of EVs through user investigation and data analysis. The V2G model includes behavior model and energy model, which reflect influencing factors such as user behavior, user preferences, and charging and discharging characteristics. 


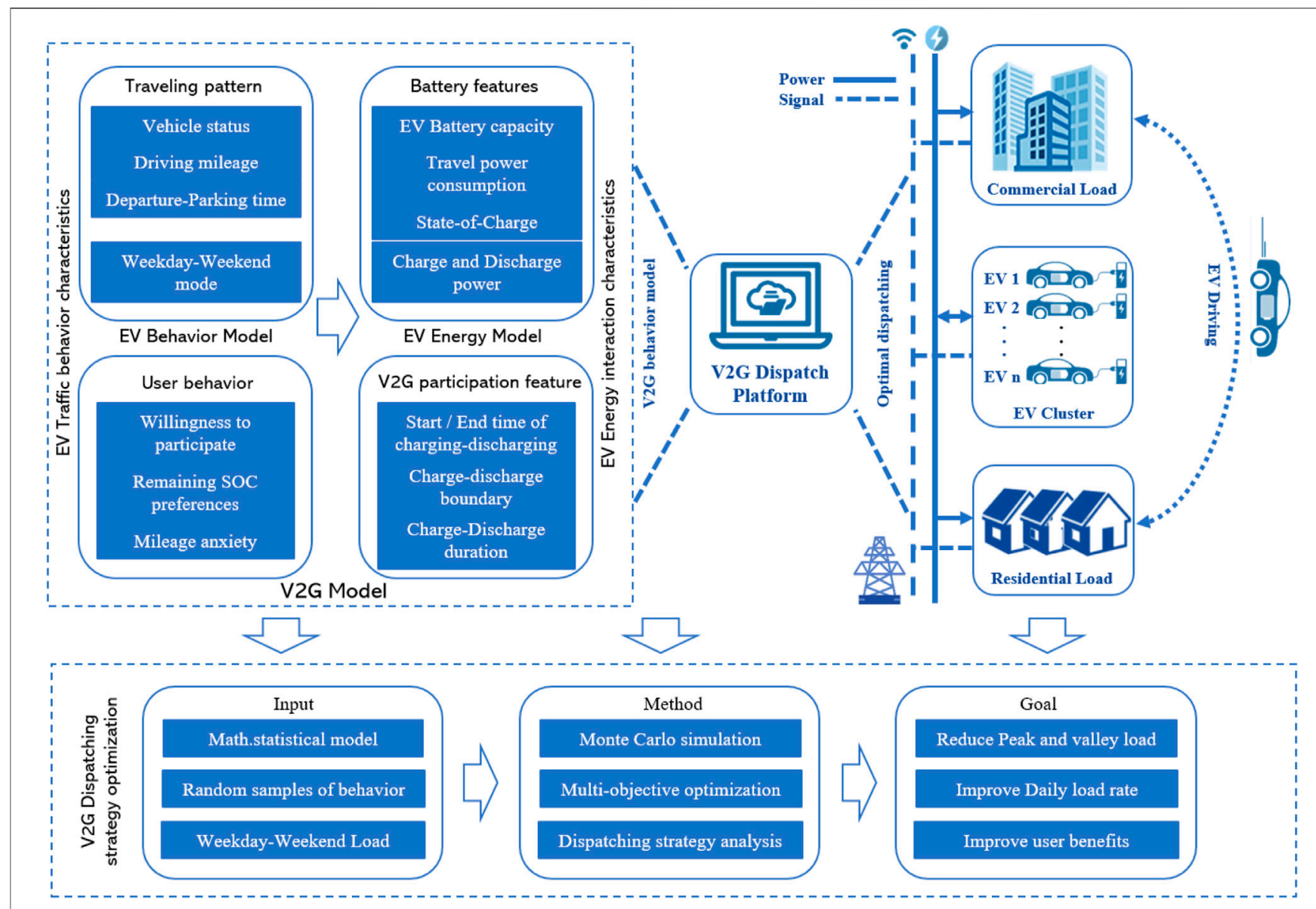

FIGURE 1 | Research structure of V2G dispatching strategy based on behaviour model.

TABLE 1 | Behaviour Model Variable factor
User driving variable

Human factor variable

\section{Parameter type}

\section{Variable factor}

Daily driving mileage Initial departure time Driving -parking duration

Willingness to participate in V2G Mileage anxiety boundary Expected SOC
Finally, in Vehicle to Grid Multi-objective Optimal Dispatching Considering Demand Response Section, Monte Carlo simulation and multi-objective evolutionary algorithm are used to optimize the $\mathrm{V} 2 \mathrm{G}$ dispatching strategy.

\section{ELECTRIC VEHICLE LOAD ANALYSIS BASED ON USER BEHAVIOR}

\section{User Behavior Survey}

The user behavior model of EVs mainly needs to consider factors such as daily driving mileage, initial departure time, driving-parking duration, mileage anxiety boundary and expected SOC. The parameter variable demand table is shown in Table 1.

At the same time, consider that EV users will face more specific scenarios, such as the travel time under different modes of weekday and weekend, V2G participation in decision-making under the psychological influence of mileage anxiety, and consideration of uncertain charging/discharging boundaries and so on, these factors will affect the characteristics of the user behavior (Dong et al., 2021). Therefore, uncertain descriptions of different user groups in different scenarios will have certain difficulties. For example, the estimation of charging time depends on the user's mileage anxiety. Existing statistical information doesn't provide data for users to participate in decision-making in the face of V2G, and it is impossible to know user preferences (Wolinetz et al., 2018).

In order to solve these problems, it is necessary to introduce preference survey in questionnaire design and data mining. The questionnaire survey method is also a research method based on experimental psychology (Wu et al., 2018). In order to study the willingness of EVs to participate in V2G, a questionnaire-based survey method was used to overcome the limitations of statistical methods (Geske and Schumann, 2018). At the same time, 


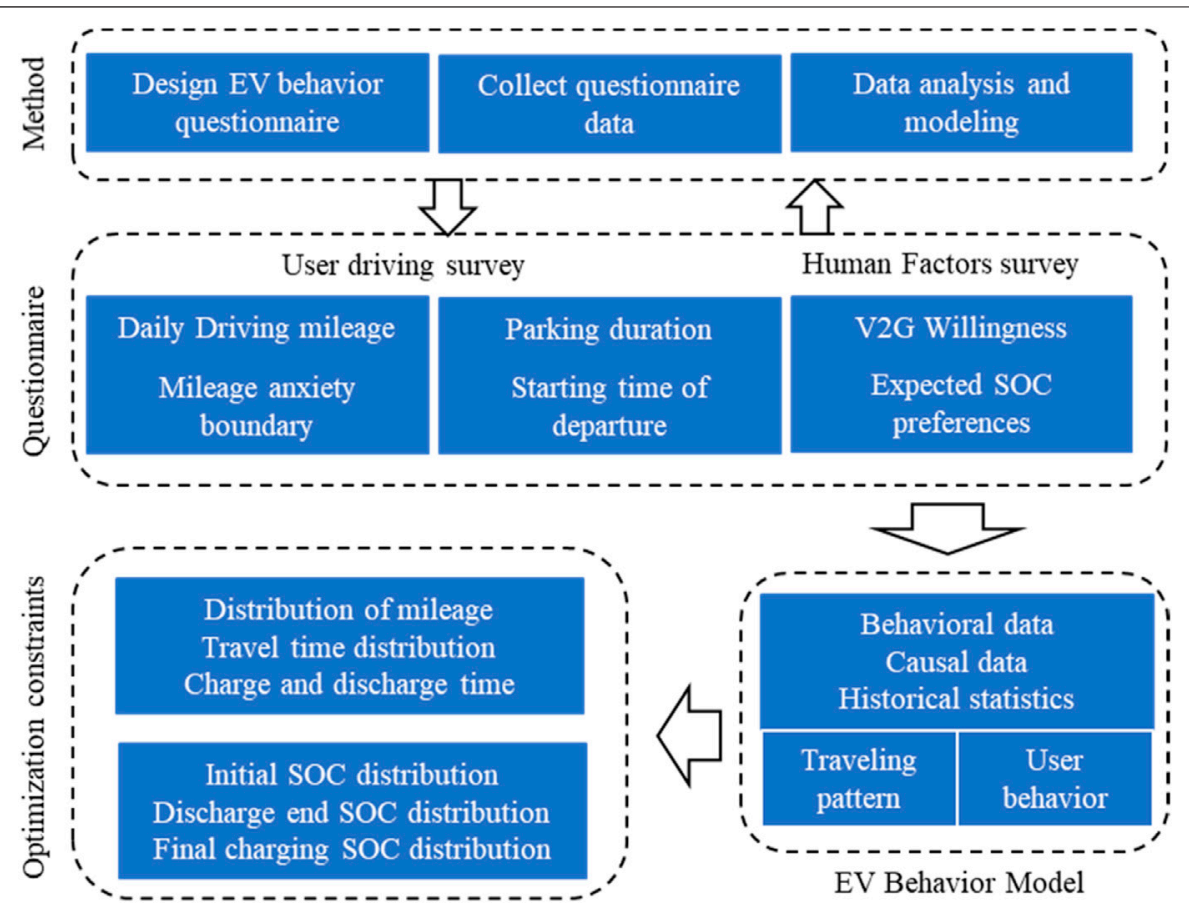

FIGURE 2 | EV Behaviour Model based on questionnaire survey.

TABLE 2 | EV user behaviour questionnaire.

Type

Questions

User Driving Variable

a. What is your average mileage on a weekday or weekend?

b. What time do you usually departure or park?

c. When do you charge the EV and how long does it take to charge?

Human Factor Variable

d. If V2G has low-carbon and economic benefits, what is your willingness to participate in V2G for electric vehicles?

e. How much EV SOC will make you feel "mileage anxiety" or "mileage sufficient"?

f. When participating in V2G on weekdays or weekend, what is the minimum remaining power you allow after discharge?

through the evaluation of psychological factors, the decisionmaking tendency of users is judged, and a behavior model reflecting the willingness of $\mathrm{EV}$ users to participate in grid operation is established. The establishment method of EV Behavior Model is shown in Figure 2.

The questionnaire will mainly investigate the parameter variables required for model and simulation, including two parts: User Driving Variable and Human Factor Variable. Set the usage scenarios as weekday (home-company-home) and weekend (home-shopping mall-scenic area-home). The content of the questionnaire is shown in Table 2.

\section{Survey Results and Behavioral Models}

A total of 380 questionnaires were distributed this time, including 320 valid questionnaires. The ratio of men to women in the questionnaire is close to $1: 1,52 \%$ are from Beijing, Shanghai, Shenzhen and other first-tier cities, and more than $94 \%$ have a university degree or above, which meets the needs of this survey on EVs. The quality of the survey is of reference value.
The survey mainly focuses on four parts: daily mileage, SOC psychological threshold, departure time and parking time, and expected SOC. Combined with NHTS traffic statistics, we can get the user behavior pattern model and the EV access probability model.

\section{1) Daily mileage}

Figure 3 shows the distribution of weekday and weekend mileage. The average weekday mileage is $35 \mathrm{~km}$, and the weekend average mileage is $126 \mathrm{~km}$.

Compared with NHTS statistics, the survey data is relatively insufficient. It can be known that $14 \%$ of household vehicles in a single day are not used, $43.5 \%$ of them have a daily mileage of less than $30 \mathrm{~km}, 83.7 \%$ of them have a daily mileage of less than $100 \mathrm{~km}$ (Wei and Li, 2017). The daily mileage can be approximated to a lognormal distribution using the maximum likelihood estimation method. The probability density function of weekday-weekend mileage distribution is as follows: 

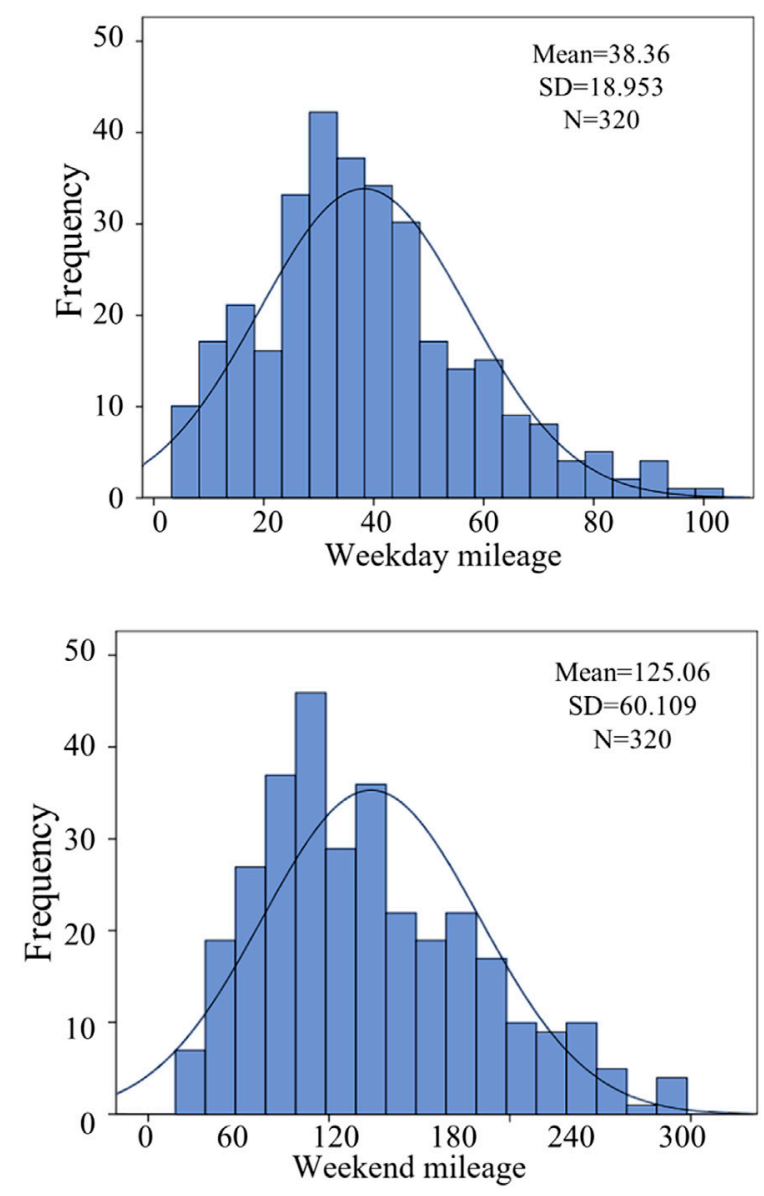

FIGURE 3 | Distribution of mileage during weekday-weekend.

$$
f_{m}(x)=\frac{1}{x \sigma_{m} \sqrt{2 \pi}} \exp \left[-\frac{\left(\ln x-\mu_{m}\right)^{2}}{2 \sigma_{m}^{2}}\right]
$$

The daily mileage model can estimate the parameters and $\eta$ of the driving distribution of a single user based on the sample mean $\mathrm{M}$ and sample variance $\mathrm{S}$.

$$
\begin{gathered}
\mu_{m}=M=\frac{1}{n} \sum_{l=1}^{n} \ln x \\
\sigma_{m}^{2}=S^{2}=\frac{1}{n-1} \sum_{l=1}^{n}\left(\ln x-\mu_{m}\right)^{2}
\end{gathered}
$$

In the weekday mode, the mean $\mu_{m 1}=38$ and the variance $\sigma_{m 1}=18$ can be taken, while in the weekend mode, $\mu_{m 2}=125 ; \sigma_{m 2}=60$.

After obtaining the probability distribution of the daily mileage, according to the assumption of power consumption and the assumption that the battery is full at the departure time, the probability distribution of the initial battery SOC of the EVs at the end of the trip can be further obtained (Lu et al., 2020).

\section{2) SOC psychological threshold}

In view of the different psychological factors of users facing different SOC levels, the questionnaire investigated the two variables of "mileage anxiety" and "mileage sufficient", and obtained the charging and discharging choices that users tend to make at a certain SOC. It can be seen from Figure 4 that when the average SOC $<31.14 \%$, the user will feel "mileage anxiety" and choose to look for charging; when the average SOC $>72.87 \%$, the user will feel "mileage sufficient" and willing to participate in V2G. When the SOC is around $50 \%$, it is in the critical stage of charging/discharging psychology, and $\mathrm{SOC}=50 \%$ can be used as the critical judgment value for $\mathrm{V} 2 \mathrm{G}$ participation, that is, when EV SOC $>=50 \%$, the discharge behavior can be selected.

\section{3) Departure time and parking time}

According to the survey of departure time and parking time, it can be known that 22:00-6:00, 10:00-18:00 are EV stay periods, and 6:00-9:00 and 18:00-21:00 are EV travel periods, the distribution of departure time and parking time is shown in Figure 5.

According to the literature (Ahmadi et al., 2020), the initial charging and discharging moments all follow a normal distribution, and the potential charging/discharging time period of users is consistent with the survey results. The specific option will be based on the user's behavior decision. The probability density function at the beginning of charging - discharging is as follows:

$$
f_{t 1}(x)=\frac{1}{\sigma_{t 1} \sqrt{2 \pi}} \exp \left[-\frac{\left(x-\mu_{t 1}\right)^{2}}{2 \sigma_{t 1}^{2}}\right]
$$

With $\mu_{\mathrm{t} 1}=2 ; \sigma_{\mathrm{t} 1}=0.5$

$$
f_{t 2}(x)=\frac{1}{\sigma_{t 2} \sqrt{2 \pi}} \exp \left[-\frac{\left(x-\mu_{t 2}\right)^{2}}{2 \sigma_{t 2}^{2}}\right]
$$

With $\mu_{\mathrm{t} 2}=12 ; \sigma_{\mathrm{t} 2}=0.5$.

\section{4) Expected SOC}

At present, users' willingness to participate in V2G cannot be obtained. Most of the previous studies have adopted the method of directly assuming the preset boundary, which is not completely consistent with the real situation. Therefore, this paper conducted a questionnaire survey on the lack of willingness to discharge boundaries and obtained the expected SOC distribution.

Analyzing the expected SOC, it can be concluded that the distribution law is shown in Figure 6. After inspection, it obeys the normal distribution. Among them, the weekday travel trajectory is simple and has a large discharge margin, which obeys the normal distribution near $47 \%$; the weekend obeys the normal distribution near $52 \%$. The probability density function of Expected SOC is as follows.

$$
f_{e 1}(x)=\frac{1}{\sigma_{e 1} \sqrt{2 \pi}} \exp \left[-\frac{\left(x-\mu_{e 1}\right)^{2}}{2 \sigma_{e 1}^{2}}\right]
$$

With $\mu_{\mathrm{e} 1}=47.2 ; \sigma_{\mathrm{e} 1}=1.65$

$$
f_{e 2}(x)=\frac{1}{\sigma_{e 2} \sqrt{2 \pi}} \exp \left[-\frac{\left(x-\mu_{e 2}\right)^{2}}{2 \sigma_{e 2}^{2}}\right]
$$

With $\mu_{\mathrm{e} 2}=52.0 ; \sigma_{\mathrm{e} 2}=1.61$. 


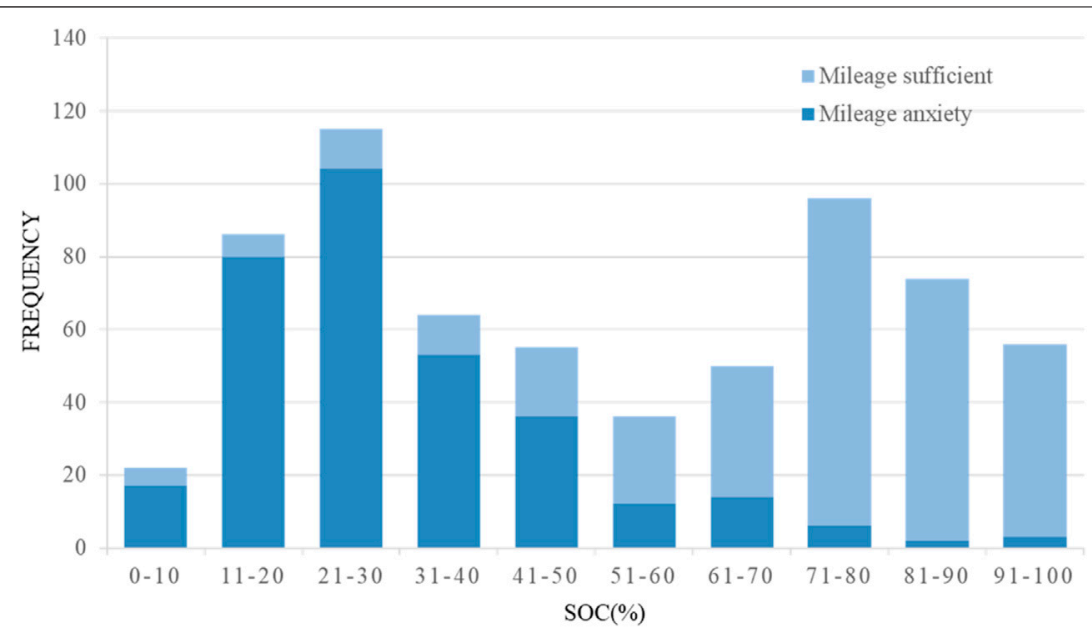

FIGURE 4 | Psychological threshold of "mileage anxiety" or "mileage sufficient".

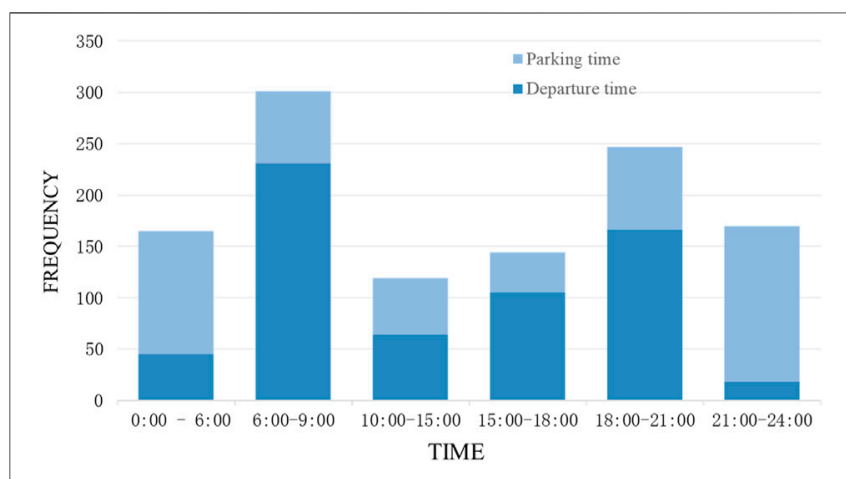

FIGURE 5 | Distribution of departure time and parking time.

\section{Electric Vehicle Charging and Discharging Model}

1) EV travel characteristics

The travel characteristics of EVs mainly include travel mileage, travel time, charging and discharging time, etc. This paper mainly according to the electric vehicle travel law, set 6:00 in the morning as the travel time, 17:00 in the afternoon as the return time, driving distance is equal. The random array of mileage is obtained from the statistical data. According to the data of national household travel survey (NHTS) (González-Garrido et al., 2019), the daily driving distance of EVs meets the lognormal distribution. Then the probability density function of daily driving distance is taken as follows.

$$
f_{m}(x)=\frac{1}{x \sigma_{m} \sqrt{2 \pi}} \exp \left[-\frac{\left(\ln x-\mu_{m}\right)^{2}}{2 \sigma_{m}^{2}}\right]
$$

Where: $\mu_{\mathrm{m}}=4.2 ; \sigma_{\mathrm{m}}=0.75$.

After obtaining the probability distribution of daily mileage, according to the assumption of power consumption $\mathrm{R}=15 \mathrm{kWh} / 100 \mathrm{~km}$ and the driving energy consumption
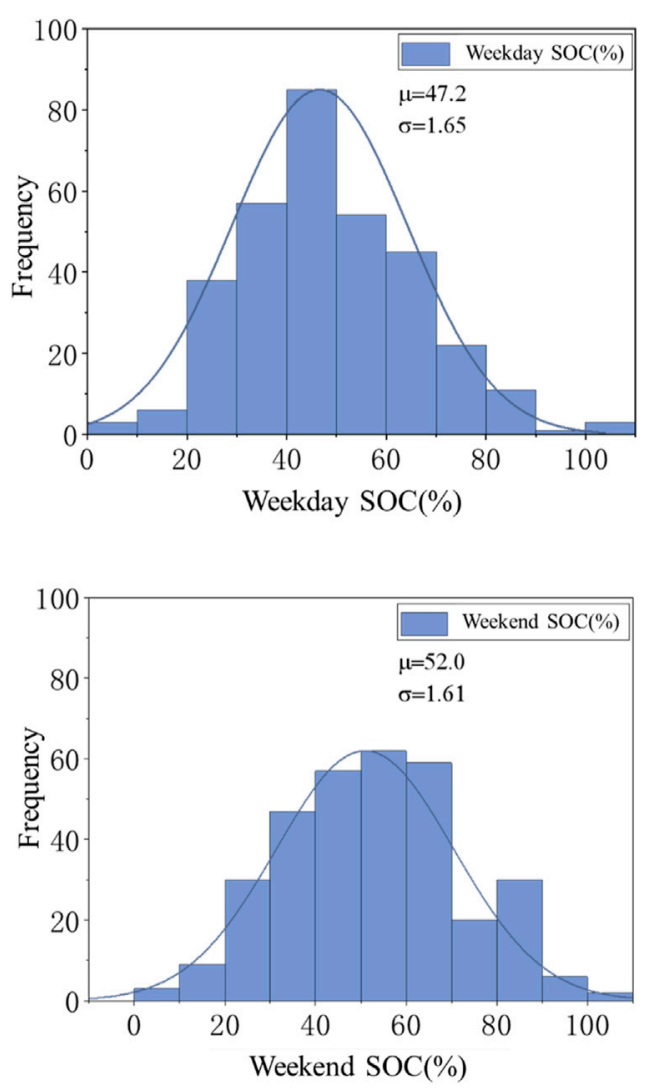

FIGURE 6 | Remaining SOC distribution after discharge.

efficiency $\eta=90 \%$ of EVs, the driving power consumption per unit time can be calculated $\Delta E_{\text {travel }}=V_{i} R \eta=6.75 \mathrm{kWh}$.

2) EV cluster load

The load curve of cluster EVs in the region can be obtained by accumulating the charging and discharging behaviors of all EVs. 
The time interval was set as 1 hour, and the load curve of 1 day was observed. The total power of charging and discharging at time $t$ can be expressed by the following formula:

$$
P_{\text {Tevi }}(t)=\sum_{i=1}^{n} P_{e v i}(t)
$$

Where: $P_{\text {Tevi }}(t)$ is the charging load of all EVs in $t$ hours, $\mathrm{i}=1,2$, $\ldots, 24 ; n$ is the total number of EVs; $P_{\text {evi }}(t)$ is the charging and discharging power of the $i$ th vehicle at time $t$.

3) State of charge (SOC)

The state of charge (SOC) of EV refers to the current state of residual power of its power battery. The SOC of electric vehicle is an important parameter to evaluate the V2G load capacity of electric vehicle. It can have starting or ending power to calculate the real-time residual power of battery. The realtime SOC change of electric vehicle battery can be expressed as follows:

$$
\operatorname{SOC}_{i}(t)=\frac{E_{e v i}(t)}{E_{e v}} \times 100 \%
$$

$\operatorname{SOC}_{i}(t)$ is the state of charge of the $i$ th vehicle at $t$, and $E_{\text {evi }}(t)$ is the remaining power of the $i$ th vehicle at $t$.

$$
E_{\text {evi }}(t)=E_{\text {evi }}\left(t_{s 1}\right)+\sum_{t=0}^{t}\left[\lambda_{v 2 g} P_{\text {evii }}(t) \Delta t-\lambda_{\text {travel } i} \Delta E_{\text {travel }}\right]
$$

Where: $E_{\text {evi }}\left(t_{s 1}\right)$ is the full power state at the starting travel time, i.e. 6:00 am. Parameters $\lambda_{\text {travel }}$ and $\lambda_{v 2 g}$ distribution represent EV driving coefficient and V2G coefficient, which are used to judge EV real-time state (driving or charging discharging).

$$
\left\{\begin{array}{l}
\lambda_{\text {travel }}=1, \lambda_{v 2 g}=0, t \in\left(t_{s 1}, t_{p 1}\right] \cup\left(t_{s 2}, t_{p 2}\right] \\
\lambda_{v 2 g}=0, \lambda_{v 2 g}=1, t \in\left(t_{p 1}, t_{s 2}\right] \cup\left(t_{p 2}, t_{\text {end }}\right]
\end{array}\right.
$$

Where: EV state coefficient is determined by the time, considering the EV user's daily driving law, morning: residential commercial area, afternoon: commercial residential area; $t_{s 1}$ and $t_{s 2}$ are the travel time of EV in the morning and return time in the afternoon, $t_{p 1}$ and $t_{p 2}$ are the travel time of two trips, and $t_{\text {end }}$ is the deadline of the next day at 6:00.

\section{Vehicle to Grid Load Analysis Based on Monte Carlo Monte Carlo Simulation}

This paper uses the V2G Model and Monte Carlo method to simulate grid operation under the charging and discharging of EVs with V2G in Shanghai. Assuming that the charging and discharging time and power of each EV are not affected by other EVs. Based on the Monte Carlo sampling method, according to the random probability distribution of each electric vehicle's driving conditions, battery characteristics, and expected SOC preferences (González-Garrido et al., 2019; Lu et al., 2020). Generate the corresponding random number to get the daily load curve of a single electric vehicle, and add up the electric

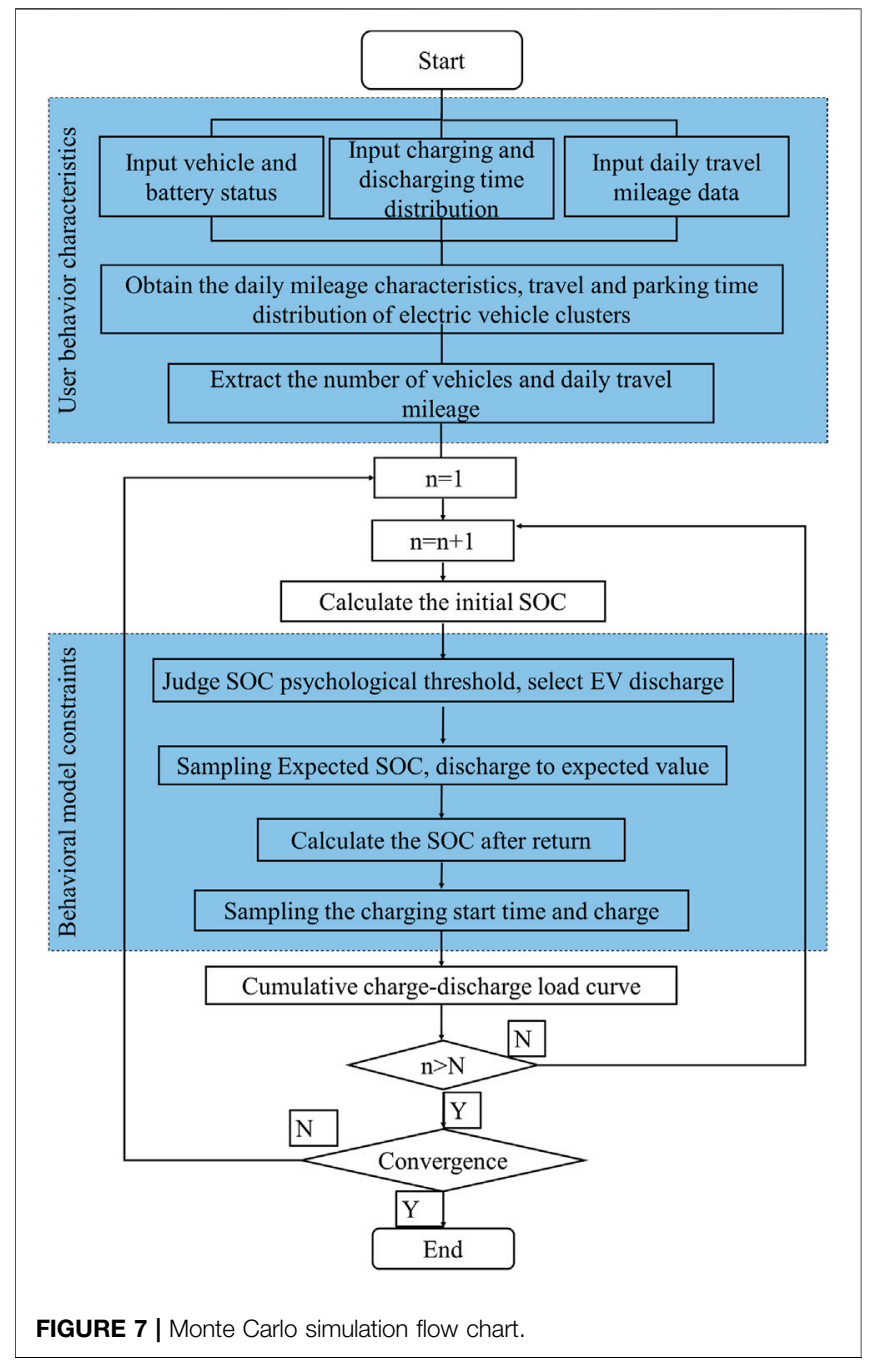

vehicle load curve to get the total load curve, the Monte Carlo simulation flow chart is shown in Figure 7.

\section{Case Analysis}

Taking Shanghai EV load regulation as an example, the scale of EVs in Shanghai in 2020 will be 300,000. The influence of regional load curve charging behavior on load is analyzed: the influence of different V2G scales and conditions on the grid load is compared. According to the EV driving data statistics and user behavior questionnaire survey, the peak load time distribution during the day coincides with the vehicle travel time. Therefore, if orderly controlled charging behavior is not adopted, large-scale disorderly charging will bring more pressure to the grid load. Further expanding the peak-to-valley load difference is not conducive to the economic and stable operation of the power grid. However, if the residence time of the EV is effectively used, the cluster V2G control mode is adopted to uniformly regulate the charging and discharging behavior of the connected EV. Set the EV to charge in an orderly manner during the low load at night after returning home, and during the daytime peak period, make full use of the energy of the EV battery and reverse 
TABLE 3 | V2G simulation parameters and variables.

\begin{tabular}{ll}
\hline Parameter & \multicolumn{1}{c}{ Variable } \\
\hline Driving mileage & $25-45 \mathrm{~km}, 110-140 \mathrm{~km}$ \\
V2G rate R & $0,30 \%, 70 \%$ \\
Remaining SOC & $30 \%-50 \%, 40 \%-60 \%$ \\
EV charge and discharge duration & Charging: 22:00-6:00, 24:00-8:00 \\
& Discharging: 9:00-12:00 and 14:00-17:00 \\
& Discharging:10:00-14:00 and 17:00-21:00
\end{tabular}

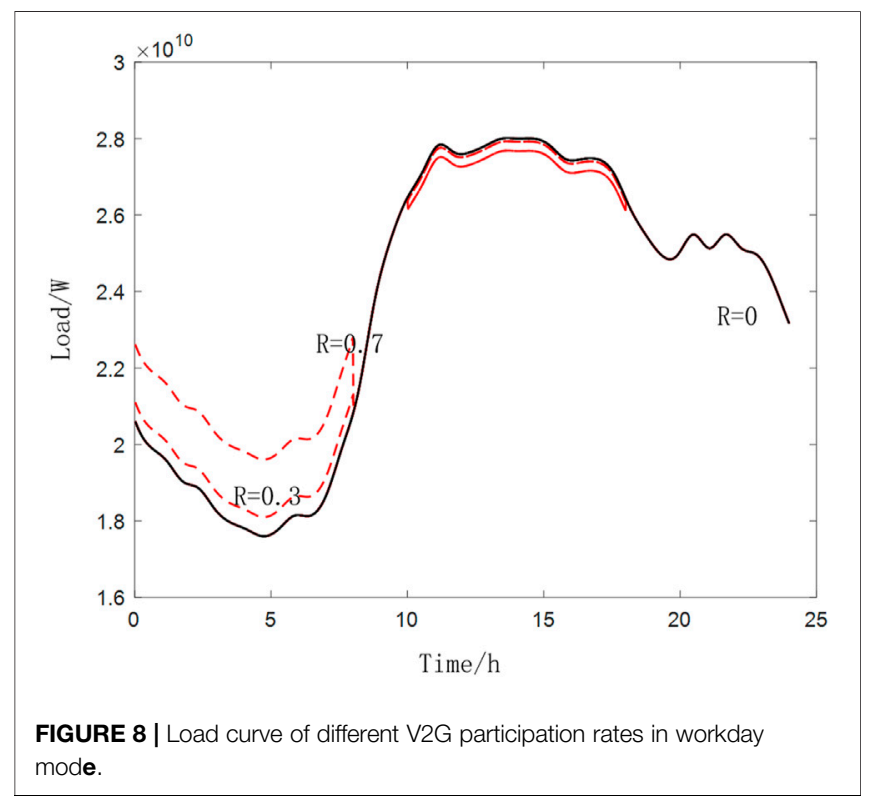

discharge the expected SOC to the grid under the premise of meeting subsequent travel and user preferences, which support peak load operation and realize the purpose of peak shaving and valley filling.

The EV will be equipped with a $60 \mathrm{kWh}$ battery, which consumes $15 \mathrm{kWh}$ per hundred kilometers. Set the parameter R to be the participation rate of electric vehicle $V 2 G$, and take the participation rate $\mathrm{R}$ to be $0,0.3$, and 0.7 , respectively. The remaining parameters are determined by the research results in Table 3 .

\section{Simulation Results}

According to Monte Carlo simulation of the cluster charging and discharging behavior of $300,000 \mathrm{EVs}$, EVs in the region are connected to the V2G platform, which can perform unified charging and discharging control of the connected vehicles, and adjust the peak and valley load of the Shanghai regional power grid. The control strategy will be determined according to the actual state information of the vehicle. The user travels at 8:00 and goes home at 17:00. The charging and discharging can be carried out when not driving. The depth of discharge is obtained from the expected SOC distribution investigated in the previous section. By superimposing the charge and discharge power of all vehicles, the total V2G load can be calculated, and finally the comparison of the grid load curves before and after EV participation is obtained. In addition, setting V2G participation

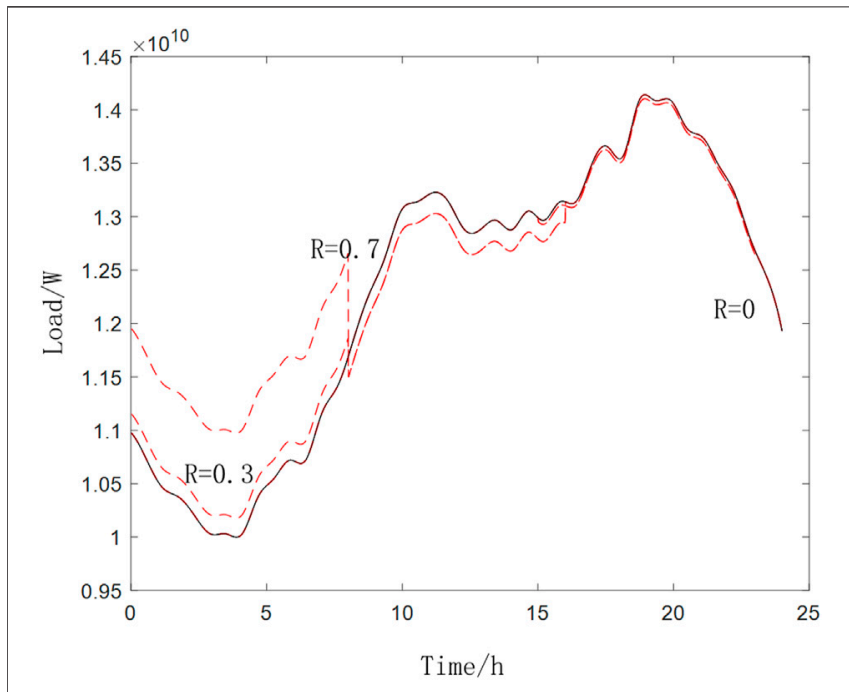

FIGURE 9 | Load curves of different V2G participation rates in holiday mode.

rates of different scales can achieve the effect of load regulation by EVs of different scales.

For the different modes of workdays and weekends, the load regulation after the participation of V2G is simulated, and the optimization curve effect is as Figure 8, Figure 9 shows.

It can be seen from Figure 8 that in the working day mode, when the $\mathrm{V} 2 \mathrm{G}$ participation rate $\mathrm{R}=70 \%$, the peak load during the day is $27685.73 \mathrm{MW}$, which is a decrease of $326.34 \mathrm{MW}$, and the valley load at night is $19607.23 \mathrm{MW}$, which is an increase of 2007.41 MW, and the peak and valley load throughout the day The difference has been changed from 37.17 to $29.18 \%$, a decrease of $7.99 \%$, and the daily load rate increased by $3.02-87.63 \%$

It can be seen from Figure 9 that in the weekend mode, when the $\mathrm{V} 2 \mathrm{G}$ participation rate $\mathrm{R}=70 \%$, the peak load during the day is $14140.67 \mathrm{MW}$, the valley load at night is $10,974.57 \mathrm{MW}$, an increase of $975.79 \mathrm{MW}$, and the peak-to-valley load difference changes from 29.29 to $29.29 \%$. $22.39 \%$, a decrease of $6.9 \%$, and a daily load rate of $88.75 \%$, an increase of $1.83 \%$ compared to before the regulation.

The results show that in the load regulation, in the working day mode, the peak-to-valley load difference can be reduced by up to $7.99 \%$, and the daily load utilization rate can be increased by $3.02 \%$. When the V2G participation rate increased from 30 to $70 \%$, the increase of $40 \%$ participation rate reduced the peak-tovalley load difference by 6 and 5.4\%, and the daily load utilization rate also increased by 2.27 and $1.27 \%$, respectively.

From the above simulation results, it can be seen that after V2G regulation, the grid load at night is more evenly distributed under the adjustment of the cluster charging, and the EV cluster during the day peak period reduces the pressure on the grid through discharge, which can stabilize the load fluctuation effect. Therefore, it can be stated when the charging and discharging of electric vehicle clusters are under unified control and management, it can effectively smooth the daytime load peaks and valleys of the power grid. 


\section{VEHICLE TO GRID MULTI-OBJECTIVE OPTIMAL DISPATCHING CONSIDERING DEMAND RESPONSE}

\section{Multi-Objective Optimization Model Multi-Objective Function}

1) Objective 1: Minimum load variance

The objective of grid side optimization mainly considers the fluctuation of daily load curve. Load mean square deviation can be used to characterize the fluctuation of grid load. The smaller the mean square deviation is, the more stable the load change is. One day is divided into 24 time periods, and the charge and discharge power of each electric vehicle in each period is the control variable. When EVs participate in peak load reduction and valley filling, they should focus on discharging at peak load and charging at low load to reduce peak valley difference. The objective function is to minimize the variance of daily load curve:

$$
\min F_{1}=\sum_{t=0}^{T}\left(P_{L}(t)+\sum_{i=1}^{n} P_{e v i}(t)-\frac{\sum_{t=1}^{T}\left(P_{L}(t)+\sum_{i=1}^{n} P_{e v i}(t)\right)}{24}\right)^{2}
$$

Where: $P_{\mathrm{L}}(t)$ represents the power of the original power grid without electric vehicle load; $P_{e v i}(t)$ represents the power of electric vehicle I at time $t$, which is a positive value for charging and a negative value for discharging; $n$ represents the number of EVs, and the time $t$ is taken as 24 .

\section{2) Objective 2: Maximum revenue for EV users}

The user side optimization target mainly considers the economy of EV users. Considering the loss cost of V2G to battery attenuation, users can obtain profits by charging at low price and discharging at high price (González-Garrido et al., 2019; Wei et al., 2021). The overall objective is determined by the profits of all users. The objective function of maximizing the profits of single day users participating in $\mathrm{V} 2 \mathrm{G}$ response is as follows:

$$
\max _{2}=\sum_{i=1}^{n} \sum_{t=0}^{T}\left[\lambda_{d} P_{e v i}(t)\left(r_{b}-r_{p}\right)-\lambda_{c} P_{e v i}(t) r_{p}\right] \Delta t
$$

Where: $r_{p}$ is the charge and discharge price of the electric vehicle in $t$ period. When $P_{e v i}(t) \geq 0, \lambda_{c}=1, \lambda_{d}=0$ means charging, otherwise, when $P_{e v i}(t) \leq 0, \lambda_{c}=0, \lambda_{d}=1$ means discharge.

At the same time, considering the cost loss caused by the attenuation of the battery capacity, the damage cost $r_{b}$ needs to be taken into consideration. The battery capacity $\mathrm{E}_{\mathrm{ev}}$ is $60 \mathrm{~kW}, \mathrm{k}$ is the number of cycles that can be used when the battery decays to $80 \%$ of its life $(3,000$ times), and the influence coefficient $\xi=0.8$. Therefore, from the formula $r_{b}=M / \xi k$, the loss cost $\mathrm{r}_{\mathrm{b}}=0.62$ yuan $/ \mathrm{kWh}$.

\section{Constraint Conditions}

1) Load fluctuation constraints of power grid
Considering that the fluctuation of power system is controlled by various indicators, excessive load fluctuation in a short time will affect the system frequency, which is not conducive to the stability of the system. When the sampling point of $0.5 \Delta t$ time interval is set, the load fluctuation rate should meet the following constraints:

$$
W_{\text {min }} \leq \frac{\left[P_{\mathrm{L}}(t+1)+\sum_{i=1}^{n} P_{e v i}(t+1)\right]-\left[P_{\mathrm{L}}(t)+\sum_{i=1}^{n} P_{\text {evi }}(t)\right]}{0.5 \Delta t} \leq W_{\max }
$$

Where: $P_{\mathrm{L}}(t)$ represents the power of the original power grid without electric vehicle load, and the load fluctuation rate $W$ is $\pm 8 \%$.

2) EV charging and discharging power constraint

$$
-\mathrm{P}_{\text {evmt }} \leq \mathrm{P}_{\text {evi }}(t) \leq \mathrm{P}_{\text {evmt }}
$$

Where: $\mathrm{P}_{\text {evmt }}$ is the maximum charging and discharging power of all EVs that can be dispatched at the $t$ stage, taking $20 \mathrm{~kW}$.

3) SOC constraint

$$
\mathrm{SOC}_{\min } \leq \mathrm{SOC}_{i}(t) \leq \mathrm{SOC}_{\max }
$$

Where: $\mathrm{SOC}_{\max }$ and $\mathrm{SOC}_{\min }$ is the maximum and minimum value of all EVs that can be dispatched, taking 0.2-0.9.

4) V2G termination constraints

In this paper, the user travel demand is specially restricted, so that the electric vehicle can meet the user's return demand after participating in $\mathrm{V} 2 \mathrm{G}$ discharge. Then the discharge state $S O C_{d i}(t)$ should satisfy:

$$
\begin{gathered}
\operatorname{SOC}_{d i}(t) \geq \mathrm{SOC}_{i_{\text {exp }}} \\
\mathrm{SOC}_{i_{\text {exp }}}=\mathrm{SOC}_{\text {min }}+\frac{d_{i} / 2 \times R \times \delta}{E_{e v}}
\end{gathered}
$$

Where: $S O C_{d i}(t)$ represents the remaining power of the $i$ th vehicle at time $\mathrm{t}$ in the discharge state, $\mathrm{SOC}_{i_{\text {exp }}}$ is the discharge termination power, indicating that the minimum remaining power should meet the power consumption required for the home mileage. $d_{i} / 2$ represents the return mileage of the vehicle $i, R$ represents the power consumption per $100 \mathrm{~km}$ of the $\mathrm{EV}$, and $\delta$ represents the conversion rate of $\mathrm{EV}$ power consumption when driving, taking 0.9 .

\section{Genetic Algorithm Optimization}

This paper presents a multi-objective optimization method for EVs to participate in V2G with the consideration of user demand response, so as to minimize the load variance and maximize the user profits. Usually, this kind of multi-objective optimization problem is to make multiple objective functions tend to be optimal under a set of constraints (Geske and Schumann, 2018; Wolinetz et al., 2018).

$$
\begin{aligned}
& \operatorname{minf}(\boldsymbol{x})=\left[f_{1}(\boldsymbol{x}), f_{2}(\boldsymbol{x}), \cdots, f_{m}(\boldsymbol{x})\right] \\
& \left\{\begin{array}{l}
h_{i}(\boldsymbol{x})=0, i=1,2, \cdots, Q \\
g_{j}(\boldsymbol{x}) \leqslant 0, j=1,2, \cdots, J
\end{array}\right.
\end{aligned}
$$


TABLE 4 | case parameters.

\begin{tabular}{lclc}
\hline Parameter & Value & Parameter & Value \\
\hline Battery capacity $E_{\text {evk }}$ & $60 \mathrm{kWh}$ & SOC & $0.2-0.9$ \\
Charge/discharge efficiency $\eta$ & 0.9 & Maximum power & $20 \mathrm{~kW}$ \\
Driving power consumption $R$ & $0.15 \mathrm{kWh} / \mathrm{km}$ & Driving speed $V$ & $40 \mathrm{~km} / \mathrm{h}$
\end{tabular}

Where: $n$ is the number of objective functions; $Q$ and $J$ are the number of equality constraints and inequality constraints respectively.

When the multi-objective genetic optimization algorithm is used to solve the charging and discharging power of EVs in an 1 hour period (i.e., the day time is split as 24 points for each EV to charge/discharge), the charging and discharging power of each $\mathrm{EV}$ in each period is taken as the position coordinate, and the dimension is $24^{*} n$ ( $n$ is the number of EVs):

$$
X_{I}=\left[\begin{array}{llll}
P_{1}(1) & P_{2}(1) & \cdots & P_{n}(1) \\
P_{1}(2) & P_{2}(2) & \cdots & P_{n}(2) \\
\vdots & \ddots & \cdots & \vdots \\
\vdots & \vdots & \ddots & \vdots \\
P_{1}(23) & P_{2}(23) & \cdots & P_{n}(23) \\
P_{1}(24) & P_{2}(24) & \cdots & P_{n}(24)
\end{array}\right]
$$

The mutation and crossover manipulation are implemented by using built-in function mutationadaptfeasible and crossoverintermediate in MATLAB (2021a, MATHWORKS, MA, USA), respectively. The population size, evolutionary generation, constraint tolerance and objective function tolerance is $200,1,000,10^{-3}$ and $10^{-6}$, respectively. When the iteration comes to 515 generation, objective function tolerance converges to $10^{-6}$, where the set of result can be plotted as a Pareto Front for both technical and economical analysis.

\section{Analysis of Vehicle to Grid Multi-Object Dispatching Cases}

This paper takes the power load of a city and the participation of EVs as an example, and then the optimization model is simulated and solved by MATLAB platform. Considering the random uncertainty of $\mathrm{EV}$ user characteristics, this paper calculates the value according to five typical characteristics of EV driving mileage, including daily short distance and medium distance travel of $30-180 \mathrm{~km}$. Case parameters are shown in Table 4.

According to the electricity price of the Shanghai power grid, the EV charging and discharging electricity price in this simulation can be set,:The Peak time (8:00-12:00, 18:00-21:00) price is 1.074 yuan/kWh, the Valley time $(23: 00-6: 00)$ price is 0.316 yuan/kWh, and the Normal time $(6: 00-8: 00,12: 00-18: 00$, 21:00-13:00) price is 0.671 yuan $/ \mathrm{kWh}$. Meanwhile, Considering the random uncertainty of EV user characteristics, this paper selects five typical travel distance types as the research objects, including daily short distance and long-distance travel of $30-180 \mathrm{~km}$, sets the number of EV participating in $\mathrm{V} 2 \mathrm{G}$ as 500 , and the mileage and quantity parameters are shown in Table 5.
TABLE 5 | Typical value of EV mileage.

\begin{tabular}{lcc}
\hline Types & \multicolumn{2}{c}{ User driving characteristics } \\
\cline { 2 - 3 } & Mileage (km) & Number of participants \\
\hline EV cluster 1 & 30 & 100 \\
EV cluster 2 & 60 & 175 \\
EV cluster 3 & 90 & 100 \\
EV cluster 4 & 120 & 75 \\
EV cluster 5 & 180 & 50 \\
\hline
\end{tabular}

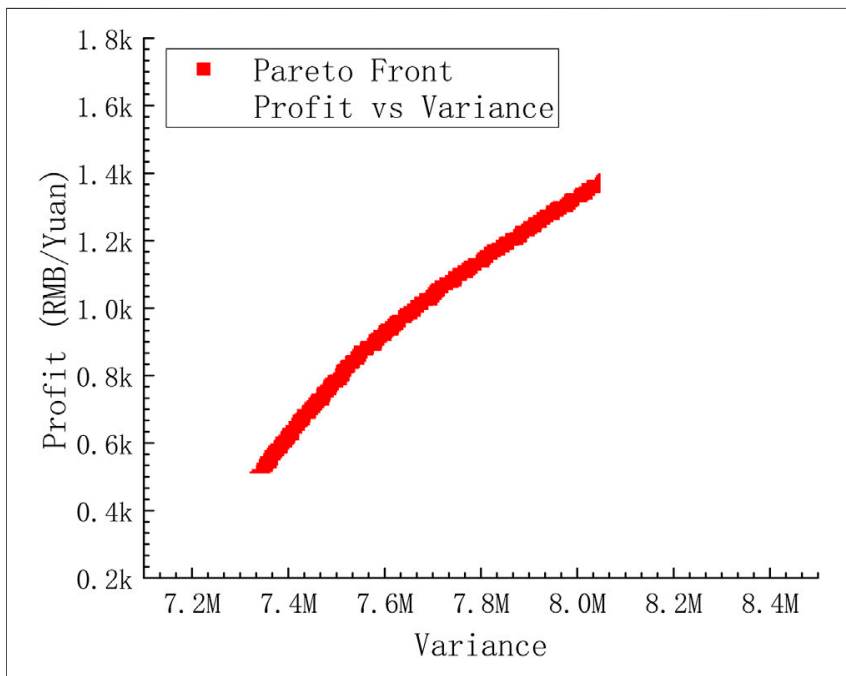

FIGURE 10 | Pareto Front-Profit vs Variance.

Through the simulation calculation of the multi-objective genetic optimization algorithm, the optimization result Pareto distribution is shown in Figure 10. Pareto distribution represents the coordination of the two objective functions of grid load variance and electric vehicle user income. It can be seen that the distribution is uniform and stable, which verifies the feasibility of Pareto optimization to solve the multi-objective problem (Lu et al., 2020).

The optimization results are closer to the actual situation, because the charging and discharging options of EVs can correspond to the time-of-use electricity price. When the grid load peaks, the price of electricity will increase, charging will decrease and discharge will increase, and revenue will increase. When the grid load is low, the price of electricity will decrease, charging will increase and discharge will decrease, and profit will decrease.

It can be seen from the Pareto Front distribution curve that the minimum variance of the grid load and the maximum revenue of electric vehicle users are difficult to achieve the optimal at the same time, and the revenue will decrease when the variance decreases. However, the distribution of the optimal solution set is relatively concentrated and the range of change is small, which can explain the multi-objective optimization problem and achieve consistency in overall regulating. There is a positive correlation between the level of time-of-use electricity price and load peaks and valleys. In the process of peak shaving and valley filling, the variance is reduced and the income is maximized. 
TABLE 6 | Comparison of power grid load changes with V2G participation.

\begin{tabular}{|c|c|c|c|c|}
\hline & User profits & Load variance & $\begin{array}{c}\text { Peak } \\
\text { valley difference (\%) }\end{array}$ & Daily load rate (\%) \\
\hline Original load & 0 & $9.24 e+6$ & 34.24 & 82.88 \\
\hline V2G regulation & $1.63 e+3$ & $8.36 e+6$ & 31.25 & 84.37 \\
\hline
\end{tabular}

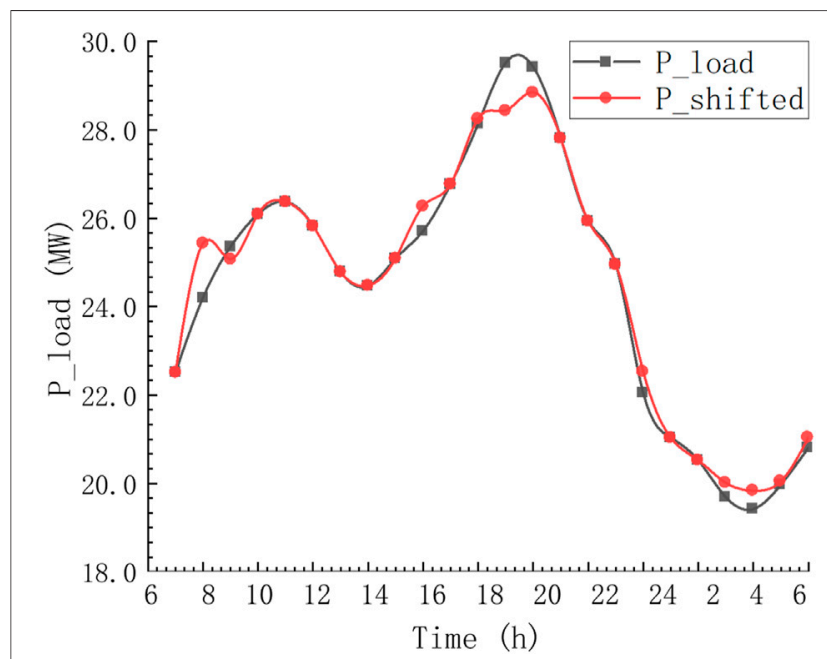

FIGURE 11 | Comparison of power grid load changes with V2G participation.

Therefore, it can be explained that after considering the needs of both the grid side and the user side, the Pareto solution set is obtained by the genetic algorithm to form a multi-objective optimal charging and discharging regulating strategy for EVs.
The optimized result graph and table are as follows. Table 6 and Figure 11 show the changes of grid load after EV participation. It can be seen that when $\mathrm{V} 2 \mathrm{G}$ participates in power grid load regulation, 1) daytime peak load decreases by $0.7 \mathrm{MW}$; nighttime valley load increases by $0.2 \mathrm{MW}$; 2) whole day peak valley load difference changes from 34.24 to $31.25 \%$, reducing by $2.99 \%$; 3) daily load rate increases by $1.49 \%$; 4 ) while user income can reach 1630 -yuan, power grid load variance decreases by $9.52 \%$.

\section{Comparison of Vehicle to Grid Response Under Different Electricity Price Modes}

In the user-side load regulation of the power system, electricity price response is an important form of demand response. Research has shown that the use of time-of-use electricity prices for off-peak power consumption can effectively reduce the burden on the grid and greatly save costs for each EV user. Due to the difference in electricity prices, the charging and discharging preferences of vehicle users are also different, so it is necessary to consider the impact of electricity price fluctuations on the optimization results (Clairand et al., 2020; Li et al., 2020). Therefore, in order to facilitate the formation of a more complete electricity price policy theory, sensitivity analysis of peak and valley electricity price fluctuations is needed.

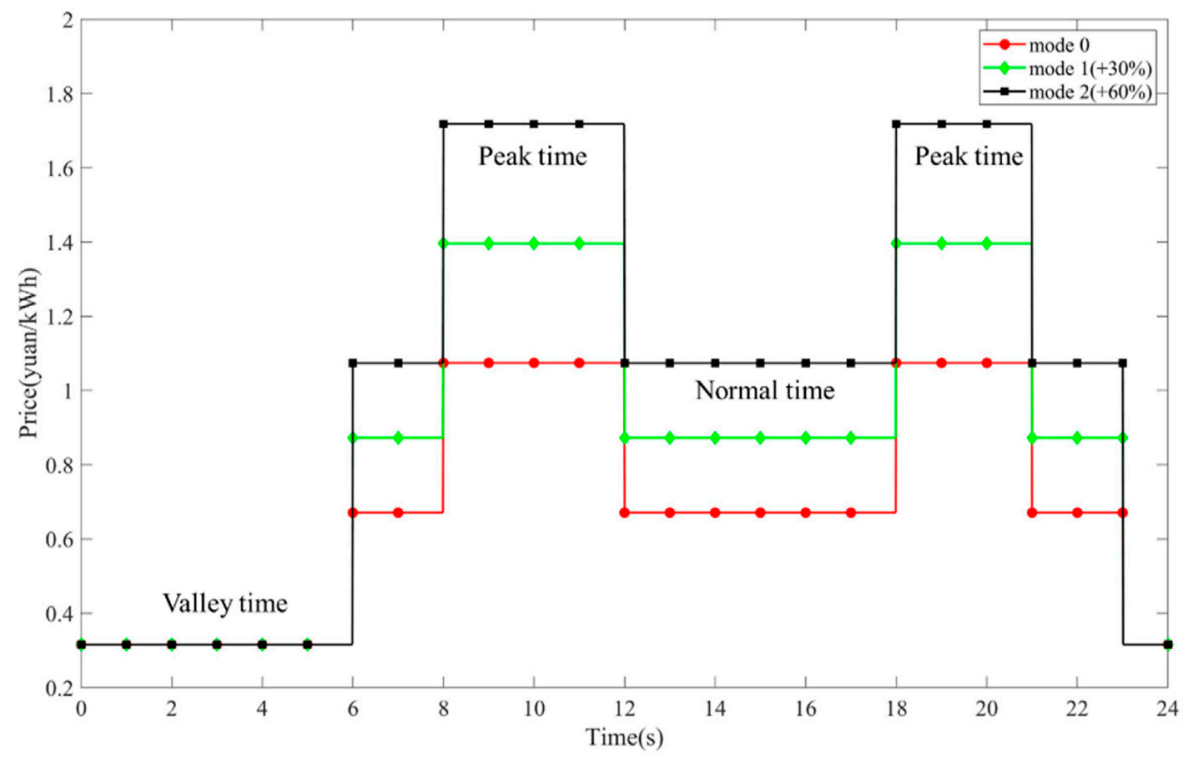

FIGURE 12 | The time-of-use electricity price model. 


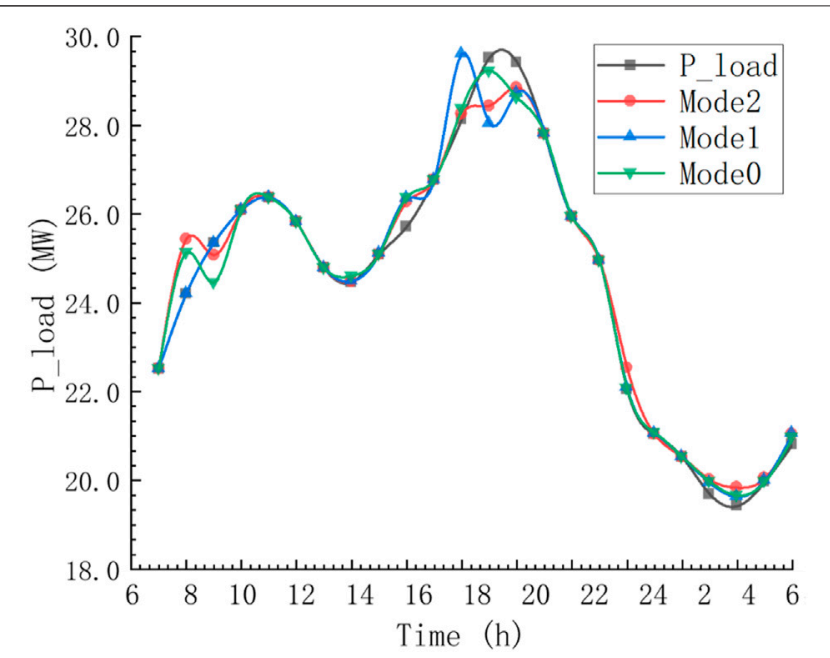

FIGURE 13 | Grid load changes in response to different electricity price modes.

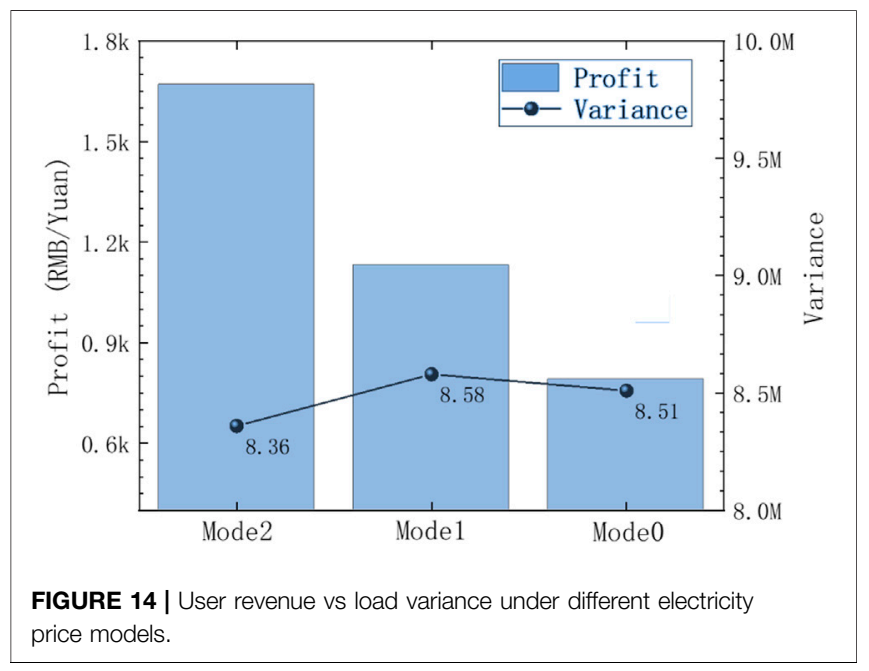

Time-of-use price (time-of-use price) refers to the establishment of three electricity price modes at different times of peak, normal, and valley to the load conditions of the power grid, so as to guide users' charging-discharging behavior and reduce the load on the grid. The time-of-use electricity price model is shown in Figure 12. Mode 0 is the current Time-of-use electricity price in Shanghai. The Peak time price is 1.074 yuan/kWh, the Valley time price is 0.316 yuan/ $\mathrm{kWh}$, and the Normal time price is 0.671 yuan $/ \mathrm{kWh}$. This section compares the current tiered electricity prices in Shanghai with the $30 \%$ (Mode 1) and 60\% (Mode 2) increase in V2G subsidized electricity prices, which is used as the charging or discharging price for EV users.

After simulation verification, the following results can be obtained. Figure 13 shows the charge and discharge power distribution of $\mathrm{EV}$ users under different electricity price modes. It can be seen from the optimization solution that the correlation between electricity price and V2G participation is not significant, but in the multi-objective game that solves the minimum variance of grid load and the maximum user economic benefit, the time-of-use electricity price guides users' charging and discharging behaviors, realizing charging during the low load period at night, and discharge during the peak load period during the day. The optimal strategy for charging during the trough period.

The economic sensitivity of EV users is different, so under a variety of electricity price modes, there will be different charging and discharging decisions. Figure 14 shows the optimization results of electric vehicle user income and load variance under different electricity price modes. The figure shows the changes in user income and load variance in response to different electricity price modes. With the increase in V2G subsidized electricity prices, user income has increased significantly, from 800 yuan under the original electricity price model response to 1,630 yuan under the $60 \%$ subsidy. An increase of $50.92 \%$. At the same time, the load variance does not decrease linearly when the electricity price increases. Compared with the response to Mode0, the variance increases by $0.82 \%$ when the electricity price is Mode1, while the variance is reduced by $1.76 \%$ when the electricity price is Mode2.

The analysis shows that with the increase in the price of the time-of-use electricity, the peak and valley electricity prices, the user's income will increase. Compared with the V2G response under the existing tiered electricity price model in Shanghai, it shows a positive correlation trend. However, the variance of the grid load is not the same as the income. A slight increase will increase the variance of the grid load, and after the electricity price is raised again, the variance can be reduced. Therefore, it can be shown that the charging and discharging behaviours of electric vehicle users are affected by the fluctuation of electricity prices, and their economic benefits can be maximized during peak load periods and charging during trough periods. At the same time, it can reduce the variance of grid load through demand response and improve the goal of stable grid operation.

\section{CONCLUSION}

In conclusion, this paper studies the V2G mode based on the user behavior characteristic by Monte Carlo simulation, the influence of the charging and discharging process of EVs on the load characteristics of the power grid is simulated and analyzed, finally the V2G cluster dispatching strategy considering the demand response of the grid side and the user side is obtained through optimization calculation.Conclusion

The optimization of $\mathrm{V} 2 \mathrm{G}$ dispatching strategy can get the following results: When the V2G participation rate increases by $40 \%$, the peak-to-valley load difference will be reduced by $6 \%$ respectively, and the daily load utilization will increase by $2.27 \%$. After adding the time-of-use electricity price incentive method, this strategy can stabilize grid load fluctuations and increase the profit of EV users. It achieves the regulating effect of reducing the peak-to-valley load difference of the whole-day grid by $2.99 \%$, 
increasing the daily load rate by $1.49 \%$, and reducing the variance of the grid load by $9.52 \%$. The goal of peak-shaving and valleyfilling under the balance between the power grid and the needs of users on both sides is completed.

It can be seen that V2G participation in grid load dispatching will be possible to effectively reduce the daily peak-to-valley difference and increase the grid daily load rate while suppressing load fluctuations, which will significantly stabilize the grid daily load curve. At the same time, through the multiobjective optimization algorithm, the simulation analysis of EV charging and discharging participating in the grid load dispatching is carried out. Finally, the optimal dispatch strategy can be obtained, which can increase the income of electric vehicle users while stabilizing the fluctuation of the grid load.

In this paper, in order to carry out quantitative comparative analysis, some assumptions are used to make EV user data more random and improve the authenticity of the model. The following papers will enrich the model data and improve the optimization algorithm to get higher quality results.

\section{REFERENCES}

Ahmadi, S., Arabani, H. P., Haghighi, D. A., Guerrero, J. M., Ashgevari, Y., and Akbarimajd, A. (2020). Optimal Use of Vehicle-To-Grid Technology to Modify the Load Profile of the Distribution System. J. Energ. Storage 31, 101627. doi:10.1016/j.est.2020.101627

Clairand, J. M., Rodríguez-García, J., and Álvarez-Bel, C. (2020). Assessment of Technical and Economic Impacts of EV User Behavior on EV Aggregator Smart Charging. J. Mod. Power Syst. Cle 8 (2), 356-366. doi:10.35833/MPCE.2018.000840

Dong, L., Wang, C., Li, M., Sun, K., Chen, T., and Sun, Y. (2021). User DecisionBased Analysis of Urban Electric Vehicle Loads. CSEE J. Power Energ. Syst. 7 (1), 190-200. doi:10.17775/CSEEJPES.2020.00850

Geske, J., and Schumann, D. (2018). Willing to Participate in Vehicle-To-Grid (V2G)? Why Not!. Energy Policy 120, 392-401. doi:10.1016/j.enpol.2018.05.004

González-Garrido, A., Thingvad, A., Gaztañaga, H., and Marinelli, M. (2019). Fullscale Electric Vehicles Penetration in the Danish Island of Bornholm-Optimal Scheduling and Battery Degradation under Driving Constraints. J. Energ. Storage 23, 381-391. doi:10.1016/j.est.2019.03.025

Jian, L. (2020). An Analysis on the Application Potential and Position of Electric Vehicle Energy Storage. J. Glob. Energ. Interconnection 000 (001), 44-50. doi:10.19705/j.cnki.issn2096-5125.2020.01.005

Kempton, W., and Tomić, J. (2005). Vehicle-to-Grid Power Implementation: From Stabilizing the Grid to Supporting Large-Scale Renewable Energy. J. Power Sourc. 144 (1), 280-294. doi:10.1016/j.jpowsour.2004.12.022

Leonori, S., Rizzoni, G., Frattale Mascioli, F. M., and Rizzi, A. (2021). Intelligent Energy Flow Management of a Nanogrid Fast Charging Station Equipped with Second Life Batteries. Int. J. Elec Power 127, 106602. doi:10.1016/j.ijepes.2020.106602

Li, X., Tan, Y., Liu, X., Liao, Q., and Wang, Z. (2020). A Cost-Benefit Analysis of V2G Electric Vehicles Supporting Peak Shaving in Shanghai. Electr. Pow Syst. Res. 179, 106058. doi:10.1016/j.est.2020.101627

Lu, Z., Zhang, Q., Yuan, Y., and Tong, W. (2020). Optimal Driving Range for Battery Electric Vehicles Based on Modeling Users' Driving and Charging Behavior. J. Adv. Transportation 2020 (3), 1-10. doi:10.1155/2020/8813137

Mahmud, K., Jahangir Hossain, M., and Town, G. E. (2018). Peak-Load Reduction by Coordinated Response of Photovoltaics, Battery Storage, and Electric Vehicles. Ieee Access 6, 29353-29365. doi:10.1109/ACCESS.2018.2837144

Qian, K., Zhou, C., Allan, M., and Yuan, Y. (2011). Modeling of Load Demand Due to EV Battery Charging in Distribution Systems. IEEE Trans. Power Syst. 26 (2), 802-810. doi:10.1109/tpwrs.2010.2057456

Salehpour, M. J., and Tafreshi, S. M. M. (2020). Contract-Based Utilization of PlugIn Electric Vehicle Batteries for Day-Ahead Optimal Operation of a Smart Micro-Grid. J. Energ. Storage 27, 101157. doi:10.1016/j.est.2019.101157

\section{DATA AVAILABILITY STATEMENT}

The raw data supporting the conclusion of this article will be made available by the authors, without undue reservation.

\section{AUTHOR CONTRIBUTIONS}

Conceptualization and methodology, TL; software: ST and KH; modeling: TL, BY, and BX; validation: ML; writing-original draft preparation: TL, KH, and ST; writing-review and editing, TL and ST; supervision: YS; project administration: YS

\section{FUNDING}

This research was funded by the National Key Research and Development Program of China (Grant No. 2019YFB2103200 and No. 2018YFB1500904).

Sangob, S., and Sirisumrannukul, S. (2021). Optimal Sequential Distribution Planning for Low-Voltage Network with Electric Vehicle Loads. Front. Energ. Res. 9, 407. doi:10.3389/fenrg.2021.673165

Soares, J., Fotouhi Ghazvini, M. A., Vale, Z., and de Moura Oliveira, P. B. (2016). A Multi-Objective Model for the Day-Ahead Energy Resource Scheduling of a Smart Grid with High Penetration of Sensitive Loads. Appl. Energ. 162, 1074-1088. doi:10.1016/j.apenergy.2015.10.181

Toquica, D., De Oliveira-De Jesus, P. M., and Cadena, A. I. (2020). Power Market Equilibrium Considering an EV Storage Aggregator Exposed to Marginal Prices - A Bilevel Optimization Approach. J. Energ. Storage 28, 101267. doi:10.1016/ j.est.2020.101267

Xiao, H., Wei, P., and Li, K. (2017). Multi-Objective Optimization Scheduling Method for Active Distribution Network with Large Scale Electric Vehicles. Trans. China Electrotechnical Soc. 32 (S2), 179-189. doi:10.19595/j.cnki.10006753.tces.L70199

Wei, W., Ramakrishnan, S., Needell, Z. A., and Trancik, J. E. (2021). Personal Vehicle Electrification and Charging Solutions for High-Energy Days. Nat. Energ. 6 (1), 105-114. doi:10.1038/s41560-020-00752-y

Wolinetz, M., Axsen, J., Peters, J., and Crawford, C. (2018). Simulating the Value of Electric-Vehicle-Grid Integration Using a Behaviourally Realistic Model. Nat. Energ. 3 (2), 132-139. doi:10.1038/s41560-017-0077-9

Wu, J., Xue, Y., Xie, D., Li, K., Wen, F., Zhao, J., et al. (2018). Multi-agent Modeling and Analysis of EV Users' Travel Willingness Based on an Integrated Causal/ statistical/behavioral Model. J. Mod. Power Syst. Clean. Energ. 6 (6), 1255-1263. doi:10.1007/s40565-018-0408-2

Xing, Q., Cheng, M., Liu, S., Xiang, Q., Xie, H., and Chen, T. (2021). MultiObjective Optimization and Dispatch of Distributed Energy Resources for Renewable Power Utilization Considering Time-Of-Use Tariff. Front. Energ. Res. 9, 68. doi:10.3389/fenrg.2021.647199

Xiong, L., Liu, X., Zhang, D., and Liu, Y. (2020). Rapid Power Compensation Based Frequency Response Strategy for Low Inertia Power Systems. Ieee J. Em Sel Top. 9, 4500-4513. doi:10.1109/JESTPE.2020.3032063

Xiong, L., Liu, X., Liu, Y., and Zhuo, F. (2020). Modeling and Stability Issues of Voltage-Source Converter Dominated Power Systems: A Review. CSEE J. Power Energ. Syst. 9, 1-18. doi:10.17775/CSEEJPES.2020.03590

Xue, P., Xiang, Y., Gou, J., Xu, W., Sun, W., Jiang, Z., et al. (2021). Impact of LargeScale Mobile Electric Vehicle Charging in Smart Grids: A Reliability Perspective. Front. Energ. Res. 9, 241. doi:10.3389/fenrg.2021.688034

Zechun, H., Yonghua, S., Zhiwei, X., Zhuowei, L., Kaijiao, Z., and Long, J. (2012). Impacts and Utilization of Electric Vehicles Integration into Power Systems. Proc. CSEE 32 (4), 1-10. doi:10.13334/j.0258-8013.pcsee.2012.04.006

Zeng, B., Sun, B., Mu, H., Wang, Y., Wei, X., and Wang, L. (2021). Comprehensive Benefit/Cost Analysis of Utilizing PEV Parking Lots as Virtual Energy Storage 
for the Energy Supply Sustainability of Future Distribution Systems. Front. Energ. Res. 9, 203. doi:10.3389/fenrg.2021.686890

Zhou, B., Zhang, K., Chan, K. W., Li, C., and Gao, X. (2020). Optimal Coordination of Electric Vehicles for Virtual Power Plants with Dynamic Communication Spectrum Allocation. Ieee $T$ Ind. Inform. 17, 450-462. doi:10.1109/ TII.2020.2986883

Conflict of Interest: ML was employed by the company State Grid Zhejiang Electric Power Co., Ltd.

The remaining authors declare that the research was conducted in the. absence of any commercial or financial relationships that could be. construed as a potential conflict of interest.
Publisher's Note: All claims expressed in this article are solely those of the authors and do not necessarily represent those of their affiliated organizations, or those of the publisher, the editors and the reviewers. Any product that may be evaluated in this article, or claim that may be made by its manufacturer, is not guaranteed or endorsed by the publisher.

Copyright $\odot 2021 \mathrm{Li}, \mathrm{Tao}, \mathrm{He}, \mathrm{Lu}, \mathrm{Xie}$, Yang and Sun. This is an open-access article distributed under the terms of the Creative Commons Attribution License (CC BY).

The use, distribution or reproduction in other forums is permitted, provided the original author(s) and the copyright owner(s) are credited and that the original publication in this journal is cited, in accordance with accepted academic practice. No use, distribution or reproduction is permitted which does not comply with these terms. 